\title{
Universal hearing screening using transient otoacoustic emissions in a community health clinic
}

\author{
H M Bantock, S Croxson
}

\begin{abstract}
Since 1993, targeted screening of high risk Camden and Islington babies has been carried out in hospital using the transient otoacoustic emission (TEOAE) technique and auditory brainstem responses (ABR). Because targeted screening is difficult to implement, a community pilot study using TEOAE was started in 1995 , covering $7 \%$ of the resident population. Although uptake has not been above $80 \%$, client satisfaction has been high and numbers requiring more detailed tertiary assessment have been modest $(0.5 \%$ of the population screened). A comparison was made between the cost of a universal neonatal screen using TEOAE and distraction testing at 7 months of age. The neonatal screen would be no more expensive to implement universally, even when equipment costs are included. A combination of a universal neonatal screen with distraction testing at 7 months for those not screened is likely to give $96 \%$ coverage of hearing screening in the first year of life. (Arch Dis Child 1998;78:249-252)
\end{abstract}

Keywords: transient otoacoustic emissions; universal screening; community health clinics; distraction testing

Very preterm infants are known to be at increased risk of sensorineural hearing loss. ${ }^{1}$ Brain stem auditory evoked potentials have been used for many years for selective screening of such high risk babies. ${ }^{2}$ Many of the factors which affect preterm infants also affect infants born at later gestations, at or near term, while the use of ototoxic drugs, the presence of dysmorphic features including craniofacial abnormalities, and a family history of deafness all predispose to sensorineural hearing loss as well. Since many term babies spend only a few hours in the maternity unit before being discharged home, it is all too easy for some high risk babies not to be offered targeted screening. However, because of the known importance of the various risk factors, targeted screening is now recommended, although its application still poses many problems - and however well applied, it will not detect the $33 \%$ of babies with severe sensorineural hearing loss due to autosomal recessive inheritance (approximately $1 / 1000$ children).

Since the original work of Ewing and Ewing, ${ }^{3}$ most districts have been using the 7 months distraction test as a universal screen, but a great deal of effort is needed to sustain adequate coverage and staff training. In some hands the yield of sensorineural loss has been good. ${ }^{4}$ However, the uptake of the distraction test is poor in many areas, ${ }^{5}$ and in others it leads to an unacceptably large follow up load on second tier clinics, with a low yield of sensorineural loss. ${ }^{6}$ It seems unlikely that the quality standards put forward by the National Deaf Children's Society in $1994^{7}$ can be achieved without a change in screening policy. In the USA, the National Institutes of Health has recommended universal hearing screening using transient evoked otoacoustic emissions (TEOAE), with testing of failures by measurement of auditory brain stem responses (ABR). ${ }^{8}$ In the United Kingdom, a recent paper by Watkin ${ }^{9}$ outlined a similar approach in an East London health district, where the testing was carried out in hospital.

As distraction test coverage within Camden and Islington had fallen below 95\%, and because of concern that targeted screening by either ABR or TEOAE was not reaching all eligible babies, we decided to examine the feasibility of universal TEOAE screening. Previous experience of targeted screening had been gained using the technique in hospital. In addition, we had tested nearly 1500 full term babies not at high risk (table 1). Of these term babies - who represented less than half the babies born in hospital between 1992 and 1995-9\% failed the TEOAE test in both ears when tested in the first few days of life. However, when tested one month later, only $0.8 \%$ failed again and had to be referred for diagnostic ABR testing. It was hypothesised that by testing at 3-4 weeks of life, the initial failure rate would be lowered. We thus investigated the feasibility of undertaking the universal TEOAE screen within a community clinic between 3 and 8 weeks of age.

\section{Methods}

POPULATION

The health district involved had a birth rate of about 4900 babies per year. A local health centre serving about $7 \%$ of the total population was chosen for the study.

\section{SCREENING PROGRAMME}

As soon as health visitors received information about new births, this was given to the research sister who carried out the TEOAE screening. An appointment was sent for babies to attend a dedicated clinic at the age of 3-4 weeks of age, and further information and encouragement to attend was given by the health visitor at the new 
Table 1 Results of TEOAE testing (initial hospital study)

\begin{tabular}{|c|c|c|c|c|}
\hline \multirow[b]{3}{*}{ Pocshoth } & \multicolumn{4}{|c|}{ Gestational age of neonate } \\
\hline & \multirow{2}{*}{$\begin{array}{l}\begin{array}{l}\leqslant 33 \text { Weeks } \\
(n=181)\end{array} \\
129(71 \%)\end{array}$} & \multirow{2}{*}{$\begin{array}{l}>33 \text { Weeks }^{\star} \text { plus } \\
\text { risk factors } \\
(n=700)\end{array}$} & \multicolumn{2}{|c|}{$\begin{array}{l}>33 \text { Weeks, no risk } \\
\text { factors } \\
(n=1492)\end{array}$} \\
\hline & & & 1198 & $(80 \%)$ \\
\hline Fail both ears & $14(8 \%)$ & $50(7 \%)$ & 132 & $(9 \%)$ \\
\hline Pass one ear & $17(9 \%)$ & $77(11 \%)$ & 162 & $(11 \%)$ \\
\hline Partial pass/small OAE & $21(11 \%)$ & & & \\
\hline Severe or profound SNL & $1(0.5 \%)$ & $6(0.9 \%)$ & 1 & $(0.07 \%)$ \\
\hline Mild SNL & 0 & $3(0.4 \%)$ & 0 & \\
\hline \multicolumn{5}{|l|}{ First screen } \\
\hline Sensitivity & $100 \%$ & $100 \%$ & $100 \%$ & \\
\hline Specificity & $93 \% \dagger$ & $94 \%$ & $91 \%$ & \\
\hline False positives & $13(7.2 \%)$ & $41(6 \%)$ & 131 & $(8.8 \%)$ \\
\hline Positive predicitive value $\ddagger$ & $7 \%$ & $\begin{array}{l}18 \% \text { (all SNL) } \\
13 \% \text { (severe SNL) }\end{array}$ & $0.8 \%$ & \\
\hline \multicolumn{5}{|l|}{ Second screen } \\
\hline Sensitivity & - & - & $100 \%$ & \\
\hline Specificity & - & - & $99.3 \%$ & \\
\hline False positives & _- & - & 10 & $(0.7 \%)$ \\
\hline Positive predictive value $\ddagger$ & - & - & $9 \%$ & \\
\hline
\end{tabular}

OAE, otoacoustic emission; SNL, sensorineural loss. ${ }^{\star}$ Representing all eligible babies born in a two year period between 1993 and 1995 . †ncludes both unilateral fails and partial passes. $\ddagger$ Predictive value of a positive test $=$ proportion of persons with positive tests who will be found to have the disease. at 0.8 and $1.6 \mathrm{kHz}, 7 \mathrm{~dB}$ at $2.4 \mathrm{kHz}$, and $8 \mathrm{~dB}$ at 3.2 and $4 \mathrm{kHz}$. The reproducibility of the test had to be better than $50 \%$. The time gate of the response was $4-12 \mathrm{~ms}$.

Those who failed in either one or both ears were seen for repeat testing one to two weeks later. At this time, babies who still lacked emissions from both ears were referred through the second tier clinic for ABR testing at the local district general hospital. The gap between the second TEOAE failure and ABR testing was usually one to two weeks. The ABR test was considered satisfactory if waves I, III, and V were present at $40 \mathrm{dBn}$ HL (hearing loss), and further follow up was in the second tier clinic, unless other clinical factors made tertiary referral necessary. Babies who did not respond to levels of $80 \mathrm{dBn} \mathrm{HL}$ were referred immediately to a tertiary, ear, nose, and throat (ENT)/ audiology centre and the management of cases with responses between 50 and $70 \mathrm{dBn} \mathrm{HL}$ was decided on an individual basis. Babies who had absent emissions in one ear or emissions at only some frequencies in both ears at the second TEOAE test were followed up in the second tier clinic. By 4 to 7 months of age it was possible to use tympanometry to identify those babies who had persisting otitis media with effusion. RICHS was used to record details of the neonatal screen and at the age of 7 months any child who had not been screened, or who had failed to attend for repeat testing following an unsatisfactory first screen, was notified to the health visitor for routine distraction testing.

COST EVALUATION

The cost of the pilot study was made up of the tester's time plus equipment costs and the cost of second tier clinic referrals and $\mathrm{ABR}$ costs.

ent noise level. For the community study, ing was most often carried out in a sound proofed room, although this was not essential if a quiet room was available. Because babies were easiest to test when asleep, they were left in car seats or slings while being tested. If awake, a feed given during the test maximised the chances of getting a good result within a few minutes. About five babies could be tested each hour.

TEOAE SCREEN TEST AND ABR

The phenomenon of otoacoustic emissions is used to test for normal cochlear function and requires normal middle ear function. Details of the Oto Dynamics IL088 instrument which we used have been described elsewhere. ${ }^{10}$

A probe containing a transducer and microphone was inserted into the external auditory meatus and was used to present stimuli and record emissions. Click stimuli of $80 \mu \mathrm{s}$ rectangular pulses were used with a peak intensity of $80 \pm 5 \mathrm{~dB}$ SPL. The equipment generated information about the testing variables, for example the stimulus and the signal to noise ratio and reproducibility of the emission recorded. The emission information was available in selected frequency bandwidths. In order to pass the screening test, a satisfactory wave stimulus between 75 and $85 \mathrm{~dB}$ SPL was needed, with a response $5 \mathrm{~dB}$ above noise level

\section{Results}

Table 2 gives details of the universal health centre pilot screen in the first year of operation (June 95 to May 96). Seventy five per cent of eligible children were screened.

The results were similar to those obtained when babies were tested in hospital, shortly after birth (table 1). There was no significant difference in the number of children failing both ears after the first test in the hospital or the community setting: $\chi^{2}(1)=0.183$ $(0.7>p>0.5$, NS). Nine per cent of babies still had no emissions measurable from either ear, so our earlier hope of having fewer false positives when testing was carried out at 3-4

Table 2 Universal community based screen in first year, fune 1995 to May 1996

\begin{tabular}{lcc}
\hline & $N o$ & Per cent \\
\hline Children eligible & 319 & 100.0 \\
Children tested & 240 & 75.0 \\
& & \\
Pass in both ears & 196 & 86.0 \\
Pass in one ear & 21 & 8.8 \\
Pass in one/both ears & 217 & 90.4 \\
Fail in both ears & 23 & 9.6
\end{tabular}

At a second test one or two weeks later, only $0.5 \%$ of the 240 children were referred for diagnostic auditory brainstem response testing. 
weeks of age was not borne out. Nevertheless, $217 / 240(90 \%)$ passed in a least one ear on the first screen and, on retesting, only $0.5 \%$ of the total population required diagnostic ABRs.

PROJECTED STAFFING COSTS FOR TEOAE SCREEN BY NURSES IN PRIMARY CARE SETTING

The current annual birth rate is 4900 and if $10 \%$ of babies required a retest, a total of 5390 tests would be expected. If eight babies were tested per session, 674 sessions would be needed each year. Thus 68 weeks of D grade whole time equivalent (WTE) nurse input would be needed. This would be increased by 17 weeks to take account of annual leave, study leave, and sick leave for up to four part time staff. Thus 85 weeks (1.7 WTE) D grade would be needed to run the service, with the addition of 0.4 WTE F grade for supervision and training. The nursing costs, at mid point of $\mathrm{D}$ grade and top of $\mathrm{F}$ grade scale, come to $£ 39000$. In addition, 0.6 WTE B grade or equivalent (as in distraction testing at present) would be needed to help with identifying and following up attenders, entering data onto RICHS, etc. This would cost approximately $£ 7080$. Thus staff costs would be $£ 46000$ a year.

EQUIPMENT COSTS

Although probes are said only to last for about 100 tests, in practice many last much longer than this, so 30 probes at approximately $£ 130$ each would probably be needed each year (£3900). Three more portable ILO88 machines would be needed ( $£ 24000)$. Ear tips, although reusable, also need to be built into the costing. Although the cost of ABR screening was $£ 355$ per test at the local district general hospital, only $0.5 \%$ required this test. The cost of this, if screening were universal, would be $£ 8700$ a year. However, given that more tests would be done, the cost is likely to be reduced by half, so about $£ 4500$ would be needed.

The annual cost for equipment, assuming all equipment has a five year life span, would be:

$\begin{array}{lr}\text { 4 Portable ILO88 machines } \times 1 / 5 & £ 6000 \text { approximately } \\ \text { Probes } & £ 3900 \\ \text { Ear tips } & £ 1000 \\ \text { Total } & £ 10900\end{array}$

Thus the staff and equipment costs each year are likely to be $£ 46000+£ 10900+£ 4500=$ $£ 61400$.

\section{Discussion}

During the year of the pilot study, $75 \%$ of neonates were screened and this rose to $80 \%$ by March 1997. It was not possible to achieve $95 \%$ uptake for several reasons. In the first place, we were not able to advertise the screen, as it was only offered on a local basis. Because of space constraints at the health centre, we were not able to carry out testing at both routine surveillance clinics. If we had been able to do this, we would probably have achieved a much better uptake, as at least $95 \%$ of children within the district attend for a six week developmental check. However, since the study was piloted, there has been an increase in the number of six week checks that are carried out in general practitioner clinics, and so dedicated TEOAE clinics are likely to be the most cost efficient in terms of staffing costs.

Unless a universal screen has a high coverage, it will inevitably have a low yield of the abnormality which is being screened for. Although previous studies, such as the Rhode Island studies, the Wessex study, and the Waltham Forest studies, have all made use of the fact that babies are a captive population for a short while in the maternity unit, this has still not led to $95 \%$ coverage. In Camden and Islington's three maternity units, many mothers and babies are discharged home within a few hours of birth, and home deliveries are increasing. When testing the 1500 full time babies in hospital between 1992 and 1995, $45 \%$ of those who required a retest had been given their first test within 24 hours of birth. Hospital based screening would involve recalling babies for retesting, which would be difficult in view of the fact that so many people change their address shortly after the baby is born. In addition, people may be reluctant to go back to hospital, finding the local health centre a more friendly environment. One of the problems of screening babies in hospital is the fluctuation in the number of new births each day. This can be smoothed out when clinics are held within the community. Because the mothers are fully recovered from the stress of childbirth they are less upset if retesting is necessary.

Given the simplicity of the test (if the baby was asleep or quiet), a second test did not add appreciably to the burden of screening. It was not satisfactory to test babies at 12 weeks of age and beyond, as they were too alert and there were more failures due to persisting otitis media with effusion. In the health centre pilot, no babies were found with sensorineural loss, but the previous hospital study picked up one case (table 1) where there were no antecedent risk factors. This baby was referred to a tertiary centre at 1 month of age and her severe deafness was confirmed and rehabilitation started well before 6 months of age. In fact, this child benefited from a cochlear implant at 2 years and although attending a partial hearing unit (located in a mainstream primary school) she has very good speech and her deafness is not immediately obvious in a social setting.

\section{SCREEN COVERAGE}

Both sensitivity and specificity are high for TEOAE testing (table 1). However, without coverage of at least $95 \%$, cases of sensorineural loss will still be missed. Data from RICHS indicate that the current uptake of the distraction test in Camden and Islington is about $80 \%$. Twenty five per cent fail a preliminary screen and most are retested before being referred to the second tier clinic. Even so, about $10-20 \%$ of children are referred to the second tier clinic, with only $1 \%$ going direct to ENT surgeons.

By combining the TEOAE screen shortly after birth with a 7 month distraction test in the second tier clinic for the remaining children, first year screen coverage would approach $96 \%$, even if only $80 \%$ attended for both tests (table 3 ). 
Table 3 Theoretical coverage of first year hearing screening with TEOAE (assuming 80\% of children are tested and $20 \%$ are appointed for distraction testing (DT), of whom $80 \%$ attend the second tier clinic)

\begin{tabular}{llllll}
\hline $\begin{array}{l}\text { No born } \\
\text { each year }\end{array}$ & $\begin{array}{l}\text { No having } \\
\text { TEOAE }\end{array}$ & $\begin{array}{l}\text { No appointed } \\
\text { for DT }\end{array}$ & $\begin{array}{l}\text { No attending } \\
\text { for DT }\end{array}$ & $\begin{array}{l}\text { No not tested by } \\
\text { TEOAE/DT }\end{array}$ & $\begin{array}{l}\text { Per cent having either } \\
\text { TEOAE or DT }\end{array}$ \\
\hline 4900 & $3920(80 \%)$ & 980 & $784(80 \%)$ & 196 & 96 \\
\hline
\end{tabular}

COST OF TEOAE SCREENING COMPARED WITH

DISTRACTION TESTING

The guidelines in the standards for distraction hearing testing established by the Community Trust require that testing is carried out by two suitably trained nurses, one of whom must be a health visitor. Costing varies according to the grade of nurse working with the health visitor. There are 4900 births each year in Camden and Islington, and assuming that all children are tested and 20\% retested, 5880 tests are needed each year. If eight children are appointed to each session, the final cost for two health visitors (+0.6 WTE B grade for administrative back up) is £72 732. The lowest estimate is $£ 61560$ for a health visitor and a D grade nurse.

At present, 15-20\% of babies screened by the distraction test are referred to the second tier clinics. This means that about 780 babies a year are referred, as the distraction test has about $80 \%$ coverage. If neonatal hearing screening was universal and the unscreened children were referred to the second tier clinic for distraction testing at 7 months, this would be roughly equal to the number of children currently being assessed following failed distraction tests. If the uptake of the neonatal screen were to increase beyond $80 \%$, the overall work in the second tier clinics should fall.

CONCLUSIONS

Hearing screening needs to be viewed in the context not just of a single screen, but of an overall awareness of the possibility of hearing impairment at any time. The health visiting staff and other health professionals working in the primary child health clinics are particularly interested in monitoring the hearing of the children they see because of the importance of satisfactory hearing in the development of speech and language. As a group of professionals, they are well placed to take on a screening role at birth, in just the same way as the school medical service has had the responsibility for a screening audiogram when children enter school. With the high uptake of immunisation programmes that is now being achieved, it should not be too difficult to alert people to the importance of a satisfactory hearing screen result, provided the methodology is satisfactorily worked out to take account of the differing local requirements. The choice of whether to screen in a hospital or community setting will depend on the ease of follow up for retesting, and hospital screening may be preferable when an area is served by one major hospital. It is most important to have an adequate mechanism for following up the results of testing, and in particular for dealing with those who do not come forward initially for testing - or for retesting, should that prove necessary. A great deal of time and effort is expended by health visiting staff in encouraging good attendance at the distraction test clinics and this is difficult to cost. In addition, access to a tertiary clinic for diagnostic testing, hearing aid fitting, and rehabilitation is needed, together with counselling and educational support.

Parents whose children are screened in the neonatal period greatly value the fact that they can see the results of the test and be reassured of their babies' potential for normal hearing; this is an important reason for satisfaction with the test, which should not be forgotten. It is likely that more than $80 \%$ of babies would be screened in the community and that reliance on distraction testing would fall dramatically. The cost of universal TEOAE screening is likely to be no more than the current cost of the distraction test and would provide greater sensitivity and specificity. The next phase of the universal screen within Camden and Islington is to submit a business case based on this paper, and to contrast community screening with the cost of neonatal screening in the three hospitals within the district, as well as one just outside where a small but significant number of children are born.

We thank Sisters Grainne O'Brien and Gill Reed and the clerical and administrative staff of the second tier clinic at Hornsey Rise Health Centre for their contribution to this work, and also the paediatric nursing and midwifery staff and the staff of the EEG department at the Whittington Hospital and the health visitors in Camden and Islington Community Trust who took part.

1 Hope PL, Hazell JWP, Stewart AL. Sensorineural hearing loss in very low birthweight survivors. Proceedings of the Scientific Meeting of the British Association of Audiological Physicians and Community Paediatric Group Manches-

Bradford BC, Baudin J, Conway MJ, et al. Identification of sensorineural hearing loss in very preterm infants by brainensorineural hearing loss in very preterm infants by brainstem aud

3 Ewing IR, Ewing AWC. The ascertainment of deafness in infancy and early childhood. $\mathcal{F}$ Laryngol Otol 1944;59:309-

4 McCormick B. Hearing screening by health visitors: a critical appraisal of the distraction test. Health Visitor 1983;56: $449-51$

5 Brown J, Watson E, Alberman E. Screening infants for hearing loss. Arch Dis Child 1989;64:1488-95

6 Edmond A, Mott A. What is the role of the distraction test of hearing? Arch Dis Child 1994;70:10-13.

7 National Deaf Children's Society. Quality standards in paediatric audiology. Guidelines for the early identification of hearing impairment. London: NDCS, 1994

8 National Institutes of Health. Early identification of hearing impairment in infants and young children. Bethesda, Maryland: NIH Consensus Statement, 1993:11:1-24.

9 Watkin PM. Neonatal oto-acoustic emissions screening and the identification of deafness. Arch Dis Child 1996;74:F1626.

10 Kemp DT, Ryan S. The use of transient evoked oto acoustic emissions in neonatal hearing screening programmes. Seminars in Hearing 1993;14:30-44. 